\title{
Disasters and Long-Term Recovery: Introduction to a Special Issue
}

\author{
Katie E. Cherry ${ }^{1}$
}

Published online: 19 August 2015

(C) Springer Science+Business Media New York 2015

On August 29, 2005, Hurricane Katrina made landfall as a Category 3 storm with catastrophic destruction and widespread loss of life across the U.S. Gulf Coast. Four weeks later, Hurricane Rita struck southwestern Louisiana and eastern Texas on September 25, 2005, forcing thousands of Katrina displaced Gulf Coast residents to relocate again (Cherry 2009; Kilmer et al. 2010). On April 20, 2010, the BP Deepwater Horizon offshore oil rig exploded and sank, killing 11 individuals and setting into motion an oil spill off of the Louisiana coast that has been called the worst humanmade environmental disaster in U.S. history. Over a 3-month period, an estimated 4.9 million barrels of oil were released into the Gulf of Mexico threatening south Louisiana's coastal environment, economy, seafood industry, and cultural heritage. A devastating technological disaster, the BP oil spill has introduced significant new life stresses for coastal residents still struggling with hurricane recovery (Cherry et al. 2015; Osofsky et al. 2011)

The burden of multiple disaster exposures over the past decade has been immense for coastal communities. The occurrence of back-to-back disasters has stretched societal infrastructures and mental and behavioral health resources thin (Osofsky and Osofsky 2013). These disasters also afford a unique opportunity to examine personal and social factors that may contribute to disaster outcomes for youth and families, as well as community-dwelling older people and those who reside in assisted living facilities. Hurricane Katrina, the costliest disaster to affect the U.S., is a tragic reminder of the need

Katie E. Cherry

pskatie@1su.edu

1 Department of Psychology, Louisiana State University, Baton Rouge, LA, USA for effective disaster preparedness and response. Consequently, the purpose of this special issue is to present a set of invited papers that illustrate post-disaster impacts from a lifespan perspective, with noteworthy implications for policy concerning long-term disaster recovery.

In overview, the first two papers in this special issue feature applied research projects conducted in the wake of the 2005 hurricanes. Marks begins with an overview of qualitative research methods, shedding light on various challenges that have perhaps stymied the widespread adoption of qualitative approaches to problems of societal significance in the social sciences. Marks then illustrates the application of a rigorous qualitative methodology using examples from prior research conducted during Katrina's immediate impact period (Marks et al. 2009; Tausch et al. 2011) and at least 5 years after the 2005 storms (Marks et al. in press). Next, Brown et al. report the outcomes of a mixed method study carried out in Florida in the aftermath of the four 2004 Hurricanes, Charlie, Frances, Ivan and Jeanne. They provide critical new evidence concerning disaster preparation for assisted living facilities, a topic that has received scant attention in prior literature.

Together, the next five papers offer a lifespan perspective on post-disaster psychological reactions. These papers report basic research projects conducted in the wake of the 2005 hurricanes with participants of different ages: children and youth (Lai, Tiwari, Beaulieu, Self-Brown, \& Kelley; King, Osofsky, Osofsky, Weems, Hansel, \& Fassnacht), young adults (Lowe, Rhodes, \& Waters), older adults (Kamo, Henderson, Roberto, Peabody, \& White), and very old adults (Stanko et al.). The last two papers in this special issue focus on the human impacts of the BP oil spill. Cherry and colleagues provide narrative data that capture the health and economic concerns of coastal residents and commercial fishers directly affected by the BP oil spill. Allen and 
D'Elia consider the human impact of the oil spill from a policy perspective. They contrast the approaches taken to determining environmental and mental health consequences, and cogently make a case for federal reform to address the human impacts of the oil spill disaster.

To summarize, the articles comprising this special issue provide new evidence regarding the psychosocial impact of multiple disaster exposures in the U. S. Gulf Coast region. They also point to three directions for future work to further our understanding of post-disaster health and well-being. First, they shed light on research methodologies that would valuably advance the literature. A convincing case is made for the benefits of mixed method research designs with a qualitative component to capture the process of post-disaster recovery. The articles also demonstrate the utility of latent class growth analysis to study trajectories of resilience and recovery (see Lai et al., and Lowe et al.). Second, it is clear from this special issue that developmental considerations specific to children and youth, community-dwelling older adults, and residents of assisted living facilities need more attention. Third, these papers collectively underscore the importance of disaster preparedness and the value of engaging an interdisciplinary response to formulate recommendations for policy and the development of federal programs.

In closing, this special issue provides critical new evidence on the long-term effects of exposure to the multiple disasters that have affected the Gulf Coast, including psychological distress, coping, and resilience. These papers may stimulate evidence-based interventions and treatment strategies to mitigate adversity, motivate further research, and inform public policy to promote successful adaptation and long-term recovery after catastrophic natural and technological disasters.

\section{References}

Cherry, K. E. (Ed.). (2009). Lifespan perspectives on natural disasters: Coping with Katrina, Rita and other storms. New York: Springer.

Cherry, K. E., Sampson, L., Nezat, P. F., Galea, S., Marks, L. D., \& Lyon, B.A. (2015). Prior hurricane and other lifetime trauma predict coping style in older commercial fishers after the BP Deepwater Horizon oil spill. Journal of Applied Biobehavioral Analysis, (in press)

Kilmer, R. P., Gil-Rivas, V., Tedeschi, R.G., \& Calhoun, L.G. (2010). Meeting the needs of children, families, and communities post-disaster: Lessons learned from Hurricane Katrina and its aftermath. Washington, D.C.: American Psychological Association.

Marks, L. D., Cherry, K. E., \& Silva, J. L. (2009). Faith, crisis, coping and meaning making after Katrina: A qualitative, cross-cohort examination. In K. E. Cherry (Ed.), Lifespan perspectives on natural disasters: Coping with Katrina, Rita and other storms (pp. 195-215). New York: Springer.

Marks, L. D., Cherry, K. E., Hatch, T. G., \& Lu, Y. (in press). Faith-based communities after a disaster: Successes and failures in the wakes of Hurricanes Katrina and Rita. In K. E. Cherry (Ed.), Traumatic stress and long-term recovery: Coping with disasters and other negative life events. New York: Springer.

Osofsky, H. J., \& Osofsky, J. D. (2013). Hurricane Katrina and the Gulf Oil Spill: Lessons learned. The Psychiatric Clinics of North America, 36(3), 371-383.

Osofsky, H. J., Osofsky, J. D., \& Hansel, T. C. (2011). Deepwater Horizon Oil spill: Mental health effects. Disaster Medicine and Public Health Preparedness, 5(4), 280-286.

Tausch, C., Marks, L. D., Silva Brown, J. S., Cherry, K. E., Frias, T., McWilliams, Z., \& Sasser, D. (2011). Religion and coping in the aftermath of Hurricanes Katrina and Rita: Qualitative themes from the Louisiana Healthy Aging Study. Journal of Religion, Spirituality, and Aging, 23, 236-253. 